\title{
Antiviral Resistance Mutations and Genotype-Associated Amino Acid Substitutions in Treatment-Naïve Hepatitis B Virus-Infected Individuals from the Indian Subcontinent
}

\author{
A.M. Ismail ${ }^{\mathrm{a}} \quad$ P. Samuel $^{\mathrm{b}} \quad$ C.E. Eapen ${ }^{\mathrm{c}} \quad$ R. Kannangai ${ }^{\mathrm{a}} \quad$ P. Abraham ${ }^{\mathrm{a}}$ \\ Departments of a Clinical Virology, ${ }^{\mathrm{b}}$ Biostatistics and ${ }^{\mathrm{C}}$ Gastrointestinal Sciences, Christian Medical College, \\ Vellore, India
}

\section{Key Words}

Antiviral therapy $\cdot$ Mutation · Drug resistance $\cdot$ Genotypes •

Hepatitis B virus · Reverse transcriptase this region. Further studies are essential to characterize the role of HBVrt amino acid substitutions in response to antiHBV therapy.

Copyright $\odot 2011$ S. Karger AG, Basel

\begin{abstract}
Background/Aims: Antiviral resistance is a major challenge to the treatment currently available for hepatitis $B$ virus (HBV). In this study, mutations that may affect the antiviral efficacy in treatment-naïve HBV-infected individuals were analyzed. Methods: Ninety-seven treatment-naïve HBV-infected individuals were included in this study. HBV reverse transcriptase $(\mathrm{rt})$ domains were sequenced and nucleotide differences were compared to GenBank wild-type sequences. Furthermore, HBV genotypes, subgenotypes and subtypes were determined by analyzing surface gene sequences. Results: An adefovir-related rtl233V mutation was identified in 4 subjects. The rtS213T lamivudine and entecavir refractory mutant was presented in 3 individuals. Altogether, drug-related, atypical and novel HBVrt amino acid substitutions were seen in 73 positions. The HBV genotypes A, C, $D$ and $G$ were depicted in 15, 21, 60 and 1 individuals, respectively. There were $17 \mathrm{HBVrt}$ amino acid substitutions that are associated with certain genotypes of HBV. Mutations in HBVrt corresponded to established surface gene mutations in 9 patients. Conclusion: This data shows that antiviral-resistant HBV strains do exist in treatment-naïve individuals in
\end{abstract}

\section{Introduction}

The goal of antiviral treatment is to achieve viral suppression. However, the virus evolves strategies to overcome the drug selection pressure, thereby escaping the antiviral action. Antiviral resistance is a major concern for the therapeutic management of hepatitis $B$ virus (HBV) infection. The incidence of lamivudine resistance at the end of 24 months in hepatitis B e antigen (HBeAg)positive and -negative patients was 39.5 and $25.9 \%$. Likewise, for telbivudine it is 25.1 and $10.8 \%$, respectively [1]. The cumulative probability of adefovir and entecavir resistance for the same duration was found to be 3 and $0.5 \%$ $[2,3]$.

With 50 million carriers, India has the second largest population of individuals with chronic HBV infection worldwide [4]. Locarnini and Mason [5] have described $\mathrm{HBV}$ drug resistance as the single most significant factor in treatment failure of HBV. All the available nucleoside/ nucleotide analogues for HBV target the reverse transcriptase (rt) domain of polymerase gene, and mutations

\section{KARGER \\ Fax +4161306 1234 \\ E-Mail karger@karger.ch}

www.karger.com
(C) 2011 S. Karger AG, Basel

$0300-5526 / 12 / 0551-0036 \$ 38.00 / 0$

Accessible online at:

www.karger.com/int
Prof. Priya Abraham, MD, $\mathrm{PhD}$

Department of Clinical Virology, Christian Medical College

Vellore 632004 (India)

Tel. +91 416228 2312, Fax +91 4162232035

E-Mail priyaabraham@cmcvellore.ac.in 
occurring in the conserved domains of HBVrt have been shown to confer resistance to antiviral drugs $[6,7]$. Furthermore, HBVrt lacks the proofreading activity and constantly evolves with substitution rates of $4.2 \times 10^{-5}$ nucleotide substitutions/site/year [8,9]. Consequently, viral mutants are generated during the course of disease, leading to the development of viral quasispecies [5]. The presence of pre-existing antiviral-resistant mutants and the mutation patterns that accumulate over time may affect the efficacy of subsequent treatments.

The typical mutations considered as primary mutations to lamivudine involve rtM204V/I, and for adefovir it is rtA181V/T and $\mathrm{rtN} 236 \mathrm{~T}[10,11]$. Other amino acid substitutions at sites rtL80I, rtI169T, rtV173L, rtL180M, $\mathrm{rtA} 181 \mathrm{~T} / \mathrm{S}$ and $\mathrm{rtQ} 215 \mathrm{~S}$ occur during lamivudine therapy to restore the replication capability, and are called secondary/compensatory mutations [12]. Likewise, entecavir-related mutations require combinations of substitutions at positions rtI169T, rtL180M, rtT184G, rtS202I, rtM204V and rtM250V $[13,14]$. The frequency of rtM204I/V mutations in lamivudine-experienced Indian patients was found to be $29 \%$ at 18 months [15].

Eight HBV genotypes (A-H) and subgenotypes within certain HBV genotypes have been identified [16]. The HBV strains are also distinguished into hepatitis B surface antigen (HBsAg) subtypes and there is a correlation between subtypes and genotypes [17]. Recently, genotype-dependent polymorphic amino acid positions in HBVrt region were identified, illustrating different genomic variability among HBV genotypes that may influence the development of drug resistance mutants [18].

Recent reports showing the existence of antiviral resistance strains in treatment-naïve hepatitis B individuals alert the need for baseline monitoring of antiviral resistance mutants [19-21]. Hence in the present study we attempted to identify and analyze the HBVrt amino acid substitutions capable of conferring resistance to antivirals in treatment-naïve $\mathrm{HBV}$-infected individuals from the Indian subcontinent. In addition, the effect of HBVrt amino acid substitutions on the overlapping surface (S) gene was also studied.

\section{Materials and Methods}

Subjects

Blood samples obtained from $97 \mathrm{HBV}$-infected individuals attending the liver clinic of a tertiary care teaching hospital in South India who were HBV DNA-positive were included in this study by convenient sampling. Subjects were recruited between April 2007 and August 2009 and were referred to the Department of Clinical Virology for HBV quantification. Plasma was separated on the same day of blood collection and was stored in aliquots at $-60^{\circ}$ until further analysis. All subjects were HBsAg-positive, hepatitis $\mathrm{C}$ virus (HCV) antibody (Ab)-negative, human immunodeficiency virus (HIV)-negative and treatment-naïve. The study was approved by the institutional review board and informed written consent was obtained from all the subjects. Clinical details and serum alanine transaminase levels (ALT) were obtained from the patient's hospital records.

\section{Serology Markers}

HBsAg and HBeAg testing were performed in EIA (Diasorin S.P.A., Saluggia, Italy). HCV Ab and HIV were screened in Ortho HCV 3.0 (Ortho Clinical Diagnostics, Raritan, N.J., USA) and Axsym HIV Ag/Ab combo (Abbott, Wiesbaden, Germany).

\section{DNA Isolation}

DNA was extracted from $200 \mu \mathrm{l}$ of blood plasma using the QIAamp DNA Blood MiniKit (Qiagen GmbH, Hilden, Germany) as per the manufacturer's instructions. Finally, the extract was resuspended in $50 \mu$ l of elution buffer.

\section{HBV DNA Quantification}

HBV DNA was quantified using artus ${ }^{\circledR}$ HBV RG PCR (Qiagen $\mathrm{GmbH}$, Hilden, Germany) in the Rotor-Gene 3000 or 6000 platform (Corbett Research, Mortlake, Vic., Australia).

\section{HBV Polymerase/rt Gene PCR}

$\mathrm{HBV}$ polymerase gene covering the entire rt region was amplified (1,323 bp) using high-fidelity platinum Taq DNA polymerase (Invitrogen, Carlsbad, Calif., USA) with a HBV DNA template of 5 in $50 \mu \mathrm{l}$ reaction volume. The primer sequences and PCR cycling conditions used have been described previously [13].

\section{DNA Purification and Sequencing Analysis}

The amplified PCR products were purified by Multiscreen HTS $_{\text {HT }}$ PCR plate (Millipore, Billerica, Mass., USA). Sequencing reaction was carried out with two sets of primer sequences, SP1- CTC CAG TTC AGG AAC AGT AAA CCC, ISP2- CGA ACC ACT GAA CAA ATG GC, HBVFS4- TGT ATT CCC ATC CCA TC, HBV4- GCT AGG AGT TCC GCA GTA TGG A [13, 22], and the ABI Prism Big Dye terminator cycle sequencing ready reaction kit. Briefly, $1 \mu$ l of the purified PCR product is mixed with 1.6 pmol of the primer, and $1 \mu \mathrm{l}$ of the ready reaction mix with $2 \mu \mathrm{l}$ of the sequencing buffer, making the volume to $10 \mu \mathrm{l}$ with nuclease-free water. The cycling conditions consisted of 25 cycles of $96^{\circ}$ for $15 \mathrm{~s}, 50^{\circ}$ for $20 \mathrm{~s}$ and $60^{\circ}$ for $4 \mathrm{~min}$. Excess salts and dye terminators were removed from the sequencing mixture using Montage $\mathrm{SEQ}_{96}$ filtration (Millipore). The sequencing reactions were run on an ABI PRISM 310 genetic analyzer (PE Applied Biosystems, Foster City, Calif., USA). Obtained bidirectional sequences were analyzed using BioEdit v7.0.9 and multiple sequence alignment was performed using the built-in CLUSTALW integrated in MEGA4 [23]. Nucleotide substitutions were revealed by comparing the study sequences with the consensus sequence of the $600 \mathrm{HBV}$ GenBank sequence (accession numbers in suppl. material www.karger.com/doi/10.1159/000323521). The consensus was generated aligning 3 different datasets. An amino acid differences table was generated and analyzed by CUBIT GUI 
Table 1. HBVrt amino acid substitutions observed in this study

\begin{tabular}{|c|c|c|c|c|}
\hline $\mathrm{rtA} / \mathrm{P} / \mathrm{S} / \mathrm{T} 7 \mathrm{D}$ & rtR110G & rtK149R/Q & $\mathrm{rtY} 245 \mathrm{C} / \mathrm{H}$ & $\mathrm{rtM} 309 \mathrm{~K} / \mathrm{I}$ \\
\hline rtH9Y & rtL115V & $\mathrm{rtF} 151 \mathrm{Y}$ & $\mathrm{rtS} 246 \mathrm{H}$ & rtA313S \\
\hline $\mathrm{rtI} 14 \mathrm{~L}$ & $\mathrm{rtI} / \mathrm{N} 121 \mathrm{~S}$ & rtR153Q/W & rtG255D & $\mathrm{rtC} 314 \mathrm{~S}$ \\
\hline rtI16T & $\mathrm{rtF} / \mathrm{I} / \mathrm{L} / \mathrm{V} 122 \mathrm{H} / \mathrm{N}$ & $\mathrm{rtI187L}$ & rtW257Y & rtQ316H \\
\hline rtA21S & rtN123D & $\mathrm{rtS} 213 \mathrm{~T}^{*} / \mathrm{N}$ & rtT259S & rtQ319R \\
\hline rtV23I & rtQ125K & $\mathrm{rtV} 214 \mathrm{~A}^{*} / \mathrm{E}$ & $\mathrm{rtD} / \mathrm{E} 263 \mathrm{~S}$ & rtT322S \\
\hline $\mathrm{rtA} / \mathrm{S} / \mathrm{T} 38 \mathrm{~K} / \mathrm{E}$ & $\mathrm{rtH} 126 \mathrm{Y} / \mathrm{R}$ & $\mathrm{rtQ} 215 S^{*} / \mathrm{H} / \mathrm{P}$ & $\mathrm{rtI} / \mathrm{L} / \mathrm{V} 266 \mathrm{R} / \mathrm{K}$ & $\mathrm{rtP} 325 \mathrm{~L}$ \\
\hline rtI/N/S/T53Y/D & $\mathrm{rtT} 128 \mathrm{~N}^{*} / \mathrm{L}$ & rtL217R & rtH/Q267L & rtT326A \\
\hline $\mathrm{rtA} / \mathrm{P} / \mathrm{S} / \mathrm{T} 54 \mathrm{Y} / \mathrm{H}$ & $\mathrm{rtM} 129 \mathrm{~V} / \mathrm{L}$ & $\mathrm{rtE} 218 \mathrm{~N}$ & $\mathrm{rtH} / \mathrm{Q} 271 \mathrm{~K}$ & rtY327F \\
\hline rtN76S/D & rtQ130P & rtS219T*/A & $\mathrm{rtV} 278 \mathrm{I} / \mathrm{T} / \mathrm{L}$ & rtA329T/V \\
\hline $\mathrm{rtS78T/Y}$ & rtL132M & $\mathrm{rtT} 225 \mathrm{~S}$ & rtN279D & $\mathrm{rtC} 332 \mathrm{~S} / \mathrm{R} / \mathrm{Y}$ \\
\hline rtV84I & $\mathrm{rtD} / \mathrm{E} 134 \mathrm{~N}$ & $\mathrm{rtI} 233 \mathrm{~V}^{*}$ & rtI290L & $\mathrm{rtK} 333 \mathrm{~A} / \mathrm{N} / \mathrm{Q}$ \\
\hline rtI91L & $\mathrm{rtS135N/Y}$ & rtP237T & rtV291T & $\mathrm{rtN} 337 \mathrm{H}$ \\
\hline rtV103I & rtR138K & rtN238S*/Q/T/H/D & rtL293I & \\
\hline $\mathrm{rtS106C}$ & $\mathrm{rtV} 142 \mathrm{E}$ & rtK241Q & rtY305F & \\
\hline
\end{tabular}

On comparison with HBV GenBank consensus sequence, amino acid substitutions in 73 positions were seen. Shaded positions include rt-conserved domain substitutions and * indicates amino acid substitutions that are crucial for antiviral resistance to $\mathrm{HBV}$.

(Free Software Foundation Inc., Boston, Mass., USA). These sequences were also analyzed for in vitro phenotypic prediction of HBV drug resistance mutations using the Genafor/Arevir-geno2pheno (hbv) drug resistance tool (Genafor, Bonn, Germany; http://hbv.bioinf.mpi-inf.mpg.de/index.php).

Nucleotide sequences generated from this study are deposited in GenBank database under accession numbers GU798963 to GU799059.

\section{HBV Surface Gene Analysis}

HBV S gene sequences were similarly analyzed to identify the overlapping mutations. HBV genotypes and subgenotypes were determined by aligning study sequences with published sequences representing all HBV genotypes and subgenotypes [16, 24, 25]. Phylogenetic analysis was performed in MEGA4 using the neighbor-joining method with a bootstrap test of 1,000 replicates and maximum composite likelihood algorithm. HBsAg subtypes were predicted by $S$ gene amino acid codons 122, 160, 127, 159 and 140 as described elsewhere [17].

\section{Statistical Analysis}

The number of HBVrt amino acid substitutions and HBV DNA level between the genotypes were compared using a Kruskal-Wallis test. A p value of $<0.05$ was considered statistically significant. Correlations between the HBV DNA level and ALT, rt amino acid substitution and age were analyzed using Spearman's correlation coefficient. The median HBV DNA and median number of rt amino acid substitution was compared between $\mathrm{HBeAg}$ status using a Mann-Whitney U test. All analysis was done using STATA 11 (StataCorp, College Station, Tex., USA).

\section{Results}

In 97 subjects, 80 (83\%) were male and the median age was 35 years (4-75 years). Sixty-three (65\%) were HBeAgpositive and there was a significant association between HBeAg status and median HBV DNA level $\left(4 \times 10^{5} \mathrm{IU} /\right.$ $\mathrm{ml} ; \mathrm{p}<0.001)$, range $219-9 \times 10^{8} \mathrm{IU} / \mathrm{ml}$. The median ALT was $40 \mathrm{U} / 1(12-624 \mathrm{U} / \mathrm{l})$ and there was a correlation between ALT and viral load $(\mathrm{r}=0.26, \mathrm{p}=0.008)$. Twentysix $(27 \%)$ individuals had a family history of $\mathrm{HBV}$ infection and 13 (13\%) had undergone surgical or dental procedures.

Comparison with HBV GenBank sequences revealed rt amino acid substitutions in 73 amino acid sites (table 1). An adefovir-related rtI233V mutation was seen in 4 patients. An antiviral-resistant mutant (rtS213T) that restores the replication fitness in lamivudine- and entecavir-experienced patients was seen in 3 patients. Likewise, rtT128N, rtV214A, rtQ215S, rtS219T and rtN238S compensatory mutations were identified individually. Atypical mutations with new amino acid substitutions in positions rtV84, rtT128, rtS213, rtV214, rtQ215, rtS219, rtP237, rtN238 and rtY245 were seen in 19 individuals. Altogether, functional domain mutations in HBVrt domains F, A, $\mathrm{D}$ and $\mathrm{E}$ were seen in 2, 5, 9 and 2 individuals, respectively. One subject had a single mutation in both the A and D domains. Additionally, novel amino acid substitutions were seen in 62 amino acid positions of the HBVrt region. rtI91L and rtL217R naturally occurring polymorphisms 


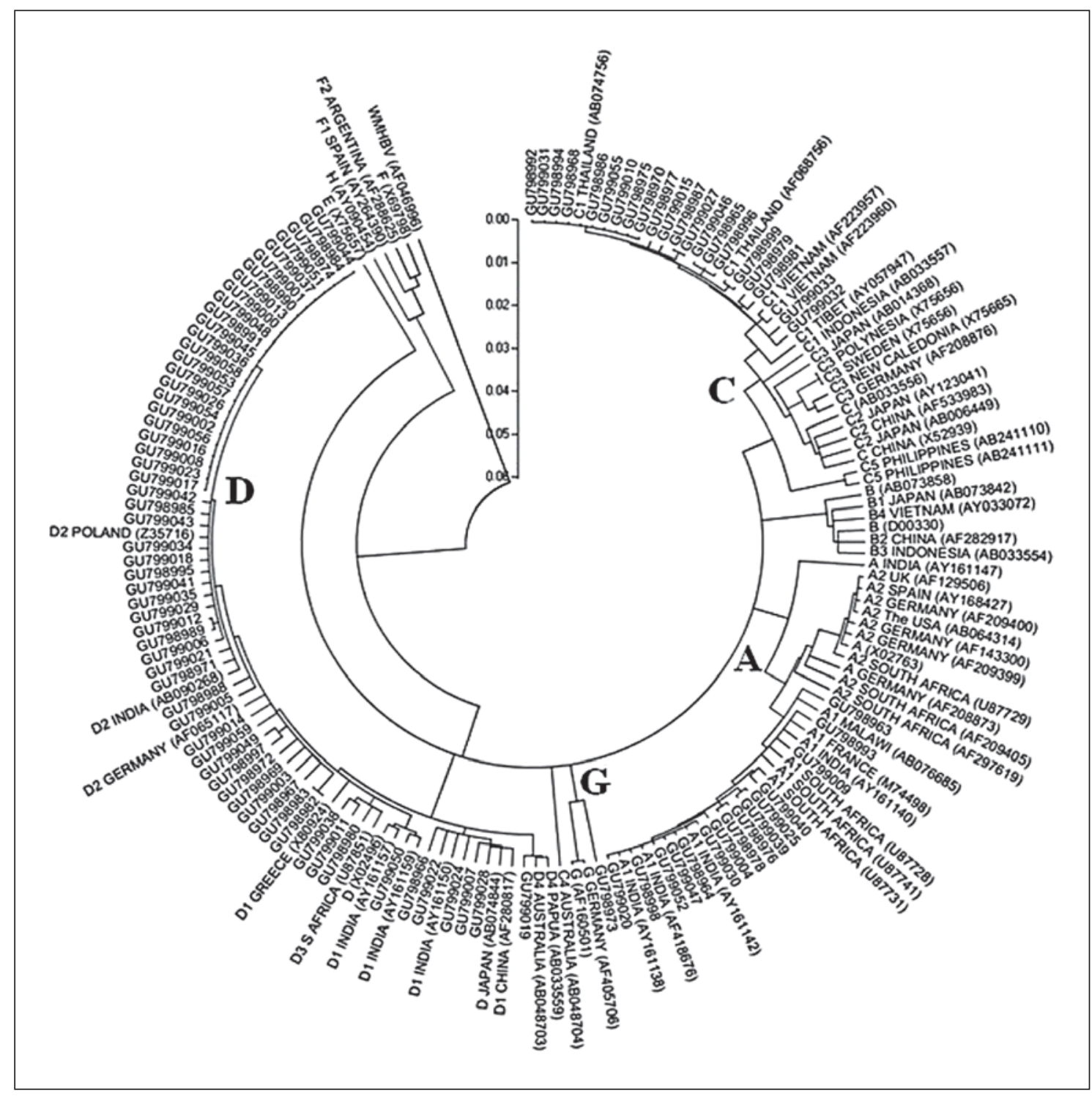

Fig. 1. Phylogenetic analysis of HBV 'S' gene sequences ( 649 positions) conducted in MEGA4 using the neighborjoining method and maximum composite likelihood model. GenBank reference strains are shown by subgenotype, accession number and country of origin. Study sequences are designated by accession number prefixed by GU. Woolly monkey HBV (WMHBV) was used as an out-group.

that respond poorly to lamivudine and adefovir were seen in 75 and 3 individuals, respectively $[26,27]$. On statistical analysis, there was a significant association between age and number of $\mathrm{rt}$ amino acid substitutions $(\mathrm{r}=0.39, \mathrm{p}<$ 0.0001 ) and a significant difference between median number of rt amino acid substitution and HBeAg status ( $\mathrm{p}=$ 0.01 ). All the study sequences when analyzed for the phenotypic prediction of drug resistance in geno2pheno (hbv) database showed adefovir resistance in 4 individuals carrying the rtI233V mutation.

HBV Drug Resistance Mutations in Treatment-Naïve Individuals
On analyzing the $\mathrm{S}$ gene, $\mathrm{HBV}$ genotype $\mathrm{D}$ was seen most commonly $(n=60)$ with the subgenotype/subtype split of D1/ayw2 $(\mathrm{n}=6), \mathrm{D} 2 /$ ayw2 $(\mathrm{n}=3)$, D2/ayw3 $(\mathrm{n}=$ 45), D3/ayw2 ( $=3)$, D4/ayw2 $(\mathrm{n}=1)$ and D5/ayw3 $(\mathrm{n}=$ 2). The HBV subgenotype/subtype A1/adw2 and C1/adr was seen in 15 and 21 individuals. One subject was infected with HBV genotype G/aywl (fig. 1 and 2). Sequence analyses also showed some HBVrt amino acid substitutions that are common and specific to certain genotypes. In the present study, rtA/P/S/T54H/Y (100\%), 


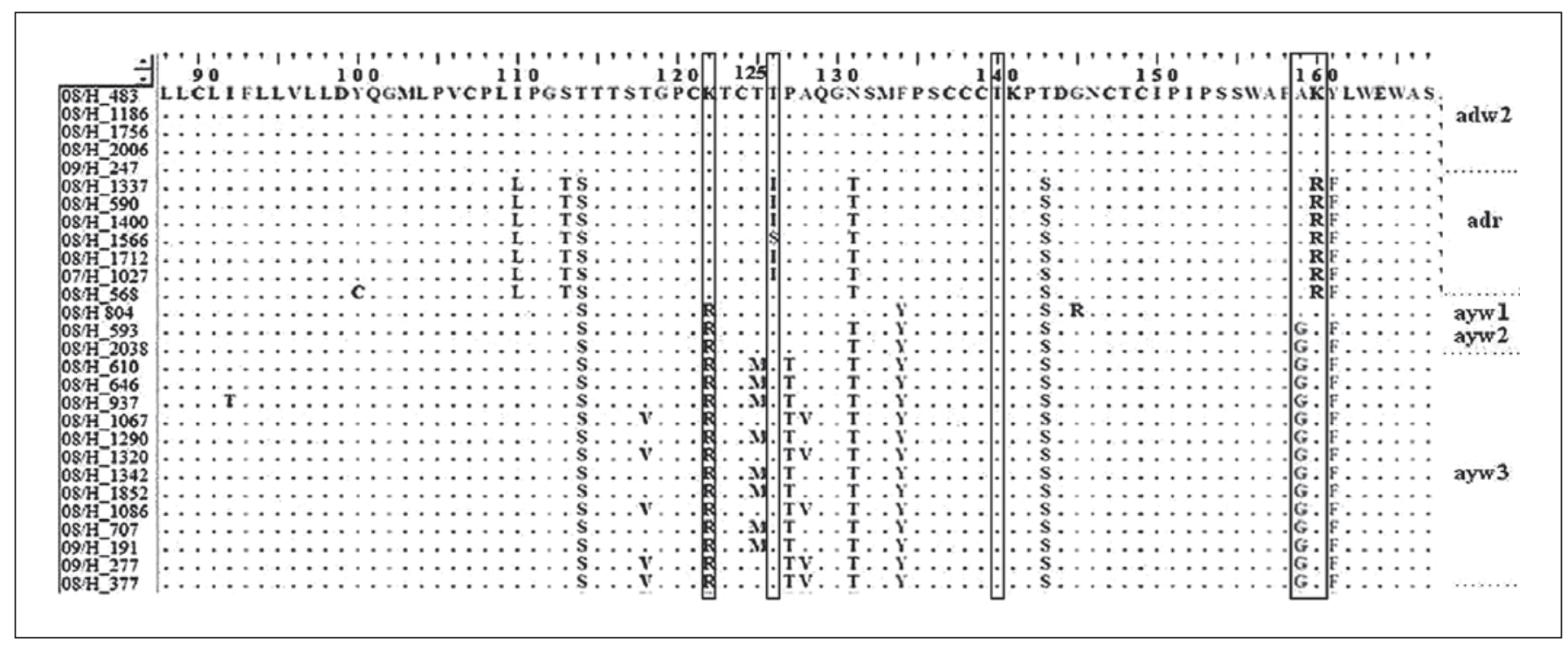

Fig. 2. HBV S gene amino acid codons showing representative samples of HBV subtype class identified in this study. Amino acid positions 122, 160, 127, 159 and 140 are used for subtype determination. Amino acid substitution sT125M is only seen in subtype ayw3 of genotype D subjects $(n=8)$.

Table 2. HBV genotype-associated rt amino acid substitutions identified in this study

\begin{tabular}{lclcc}
\hline Genotype & rtV103I & rtF/I/L/V122H & rtM129L & rtV278I/T/L \\
\hline $\mathrm{A}(\mathrm{n}=15)$ & $15(100)$ & $7(47)$ & $15(100)$ & 0 \\
$\mathrm{C}(\mathrm{n}=21)$ & 0 & 0 & $2(9)$ & $14(67)$ \\
$\mathrm{D}(\mathrm{n}=60)$ & $1(1.67)$ & $4(6.66)$ & $2(3.3)$ & $1(1.67)$ \\
\hline $\mathrm{p}$ & $<0.0001$ & 0.0004 & $<0.0001$ & $<0.0001$
\end{tabular}

Values in parentheses represent percentages.

rtS135Y/N (78\%), rtK149Q (83\%), rtW257Y (88\%), rtT259S (98\%) and rtI/L/V266R/K (18\%) were only seen in HBV genotype D. Specifically, rtI/N/S/T53D and rtH126R was observed in subgenotypes D2 with a frequency of 83 and $87 \%$ respectively. Likewise, rtF151Y and rtR153W/Q was specific to all study samples of HBV genotype $\mathrm{A}$, while $\mathrm{rtF} / \mathrm{I} / \mathrm{L} / \mathrm{V} 122 \mathrm{~N}$ and $\mathrm{rtC} 332 \mathrm{~S}$ were seen in 53 and $87 \%$ of this genotype, respectively. In HBV genotype $\mathrm{C}$ populations, $\mathrm{rtH} 9 \mathrm{Y}(100 \%)$ is the only substitution that was specific to this genotype. In addition, some of the rt amino acid substitutions are specific to certain genotypes and are shown in table 2.

There was a significant difference between HBV genotypes and the mean number of HBVrt amino acid
Table 3. Number of HBVrt amino acid substitutions with respect to HBV genotype

\begin{tabular}{lrrrr}
\hline \multirow{2}{*}{$\begin{array}{l}\text { Number of HBVrt } \\
\text { amino acid substitution }\end{array}$} & \multicolumn{4}{l}{ HBV genotype } \\
\cline { 2 - 5 } & $\mathrm{A}$ & $\mathrm{C}$ & $\mathrm{D}$ & $\mathrm{G}$ \\
\hline $1-5$ & 0 & 20 & 7 & 0 \\
$5-10$ & 15 & 1 & 48 & 1 \\
$>10$ & 0 & 0 & 5 & 0 \\
\hline
\end{tabular}

substitutions between the $\mathrm{A}$ and $\mathrm{C}$ genotypes, and between the $\mathrm{C}$ and $\mathrm{D}$ genotypes ( $\mathrm{p}<0.0001$, respectively), but no significant difference was found between genotypes A and D. However, 5 (12\%) of the genotype D subjects had $>10$ amino acid substitution (table 3 ). The difference in HBV DNA load and genotype was not statistically significant.

On comparison of overlapping S gene sequences with reference sequences, amino acid substitutions were seen in 57 amino acid positions. The rtR153Q substitution corresponded to the sG145R vaccine escape mutant in 1 patient infected with HBV genotype G, and amino acid substitution sP120T corresponding to rtT128N was seen in another patient. Likewise, neutralizing antibody escape mutants sI/N/T126S and sK141E were detected in 2 and 1 patients, respectively. The rtS78T substitution re- 


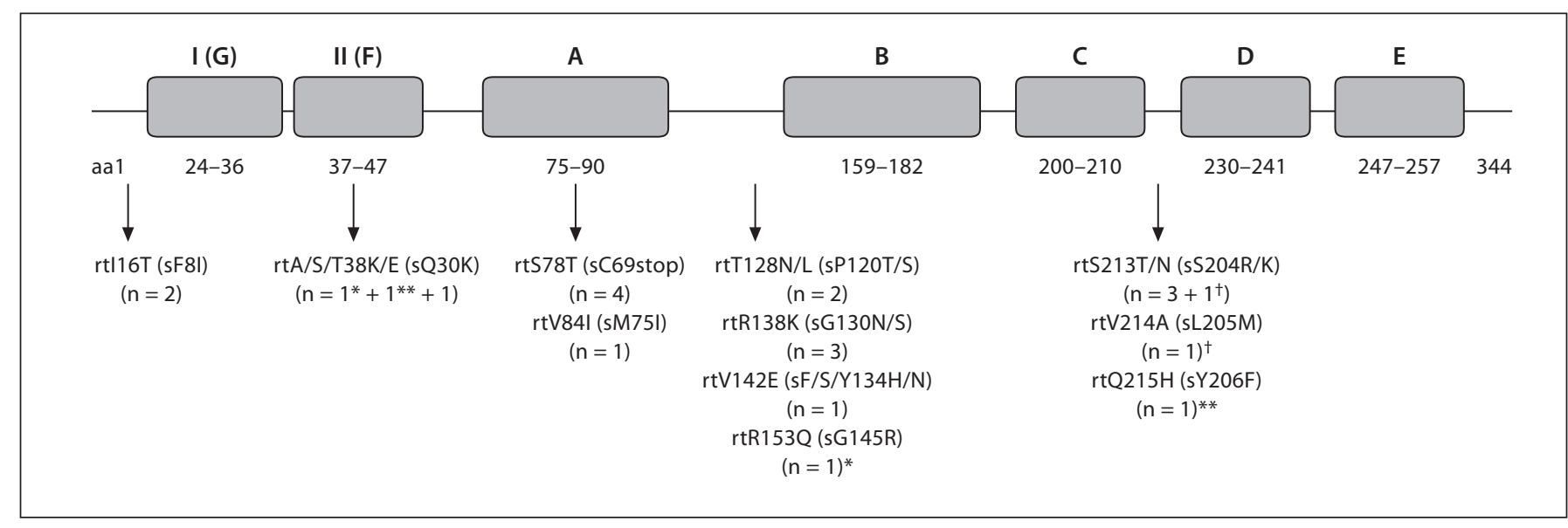

Fig. 3. HBVrt amino acid substitutions conferring overlap surface gene mutations. HBVrt domains (A-G) and respective amino acid (aa) positions are shown [45]. ' $n$ ' indicates number of patients. One patient $\left(^{*}\right)$ presented with substitution in positions rt38 (s30) and rt153 (s145), another patient $\left(^{* *}\right)$ had $\mathrm{rt38}(\mathrm{s} 30)$ and $\mathrm{rt215}(\mathrm{s} 206)$ substitutions and one patient $\left({ }^{\dagger}\right)$ carried $\mathrm{rt} 213$ (s204) and rt214 (s205) amino acid substitutions.

sulted in a sC69 stop codon mutation in 3 patients. Overall, HBVrt amino acid substitutions resulted in 'S' gene amino acid changes in 11 positions (fig. 3).

\section{Discussion}

In this study, we have described HBVrt amino acid substitutions from $97 \mathrm{HBV}$-infected subjects who have not experienced antiviral drugs to HBV. As is widely reported, the HBeAg positivity and raised ALT levels correlated with higher HBV DNA loads in these individuals. We attempted to identify novel amino acid substitutions by comparing the study sequences with maximum wildtype sequences from GenBank. This allowed us to identify some unique mutations that are drug-related, atypical amino acid substitutions in positions of known antiviral resistant target sites [20] and some novel amino acid substitutions not yet reported in the literature. There was a significant positive relationship between the age of HBV-infected individuals and the number of $\mathrm{rt}$ amino acid substitutions. As discussed by Solmone et al. [28], this may be due to the accumulation of substitutions in older age groups.

Previously, this laboratory has reported prevailing circulation of HBV genotype D followed by A and C from chronic hepatitis B groups $[29,30]$. The present study also shows a preponderance of genotype $\mathrm{D}$, but the frequency of genotype C (22\%) exceeded that of genotype A (15\%). This may be due to the inclusion of more subjects from eastern India (42/97, 43\%) where genotype $\mathrm{C}$ is common $[31,32]$. In our study, subgenotype D1, D2, D3 and D5 were seen with a frequency of $10,80,5$ and $3.3 \%$, respectively, which is comparable to an earlier report [33]. One patient from Bhutan was infected with HBV subgenotype D4 and had a unique rtE/D263S and rtA329V substitution. Banerjee et al. [34] and Kumar et al. [35] reported a sT125M mutation in the 'a' determinant region of the $\mathrm{S}$ gene to be associated with the ayw3 subtype of genotype D. A similar finding was obtained in the ayw3 subtype of D2 (16\%) and D5 (100\%) subgenotype in our study subjects. It has been reported by Norder et al. [16] that this mutant is associated with intravenous drug use. However, family history of jaundice and surgical procedures were the only risk factors of HBV infection in our study subjects. One patient carried HBV genotype G, which has been previously reported from countries like France, Germany, USA, Mexico and more recently from an Indian patient with occult HBV [35]. Intriguingly, there was no history of travel or receipt of imported blood products in this individual. The presence of HBV genotype G in our study population alerts us that larger studies may reveal genotypes from geographically distant regions.

In samples analyzed, no known 'hot-spot' mutations that can independently affect the antiviral susceptibility were seen. The rtI233V mutation common in HBV genotype $\mathrm{D}$, which can affect the antiviral efficacy to adefovir, was seen in 4 subjects: 3 (5\%) HBV genotype D and 1 (4.76\%) genotype $\mathrm{C}$, respectively [36]. In analyzing our study sequences, this is the only HBVrt mutation that 
showed a resistance profile to adefovir in the geno2pheno (hbv) drug resistance tool. Recently, Schildgen et al. [37] showed adefovir failure due to the pre-existing rtI233V mutation. However, the role of the rtI233V mutation and adefovir response remains contradictory $[10,38,39]$.

Structural biology studies have shown that HBVrt C-D interdomain mutations at rt215 and rt219 can alter the nucleotide triphosphate binding active site [7, 12]. Amino acid substitutions in each of these positions were identified in 5 individuals. Likewise, the rtS213T mutation that re-establishes the replication fitness to lamivudine and entecavir therapy was seen in 3 individuals. Amino acid substitutions at rt214, rt237 and rt238 that lie in close proximity to lamivudine-, adefovir- and entecavir-related key signature mutations were also seen. In addition to these HBVrt interdomain substitutions, functional mutations in the conserved domains $\mathrm{A}-\mathrm{E}$ were seen in 17 subjects. HBVrt shares a good sequence homology in the catalytic regions of HIV domains A-G [7]. Unlike HIV, there have been no reports of domain $\mathrm{F}$ antiviral-related mutations for HBV [40]. In our study, rtA/S/ $\mathrm{T} 38 \mathrm{~K}$ in the $\mathrm{F}$ domain was seen in 2 subjects and the role of this substitution needs to be established. Likewise, predominant substitution of rtW257Y and rtN248H in E domain is noteworthy.

Comparison to the GenBank consensus sequence allowed us to identify some unique amino acid substitutions that are genotype-specific and some substitutions that are common across certain subgenotypes/subtypes. Identification of more specific genotypic markers will aid in framing an algorithm for genotype/subgenotype classifications just like specifying HBsAg subtypes. This will also pave the way to identify markers that are predictors of response and nonresponse to HBV drugs. A2 subgenotypes containing L217R polymorphisms are shown to respond poorly in adefovir-treated individuals. This polymorphism was seen in 2 of our D2 subgenotypes and 1 C1 subgenotypes. The rtI91L naturally occurring polymorphism is predominantly seen in lamivudine-failure patients. This polymorphism was found in HBV genotype C, D and G in our study subjects and all genotype A patients in this study had rt91I. Better characterization of naturally occurring polymorphisms and drug-related resistance mutations are required for pointing out genotypic markers of response and nonresponse. All individuals carried at least 1 amino acid substitution when compared to the previously reported GenBank sequences. Statistical analysis of the number of HBVrt mutations in relation to HBV genotypes showed a significant difference between genotypes $\mathrm{A}$ and $\mathrm{C}$ and between $\mathrm{C}$ and $\mathrm{D}$.
HBV genotype D showed a larger number of substitutions (10-14 substitutions) in 5 individuals. This can potentially have clinical significance in India due to the high burden of chronically infected individuals, extensive usage of antiviral drugs and predominance of genotype D.

The surface gene of HBV is entirely overlapped by the $\mathrm{HBVrt}$ region, so mutations occurring in one region may affect the protein coding sequences of the other. HBVrt substitutions resulted in HBV S codon changes in 12 positions. The sG145R vaccine escape mutant and sP120T mutant seen in our study subjects have been shown to partially restore the replication of lamivudine resistant strains in vitro [41]. As reported, these vaccine escape mutants and truncated proteins may have an important effect on immune recognition and diagnostic testing [42]. Some naturally occurring baseline $S$ gene mutations previously reported in Indian patients with virological breakthrough was not seen in our patients, except the sA $128 \mathrm{~V}$ mutation that was seen in $40 \%$ of the individuals [43].

This is the first report from the Indian subcontinent to characterize the HBVrt sequence from treatment-naïve individuals. Our findings expand the results of earlier published studies on antiviral-resistant mutants to HBV and overlap $S$ gene mutants. According to present knowledge, the incidence of antiviral resistance is comparatively higher in HBeAg-positive individuals. In our study, HBeAg-negative variants had a higher number of rt amino acid substitutions compared to the HBeAg-positive group. It is reasoned that higher number of $\mathrm{rt}$ amino acid changes in the active domain may affect the enzyme activity reducing the replication efficacy of the virus and contribute to treatment response [44]. Follow-up of these individuals is essential to identify if a greater number of rt amino acid substitutions in HBeAg-negative patients can reduce the risk of treatment failure.

Lamivudine is the first orally available drug for HBV and adefovir remains an alternative drug of choice from 2002. As observed in this study, the chance for the presence of pre-existing HBV variants resistant to these drugs is higher when compared to the more newly introduced drugs like entecavir, telbivudine and tenofovir. Hence, to better understand the significance of the observed amino acid substitutions, structural biology studies or phenotypic testing and follow-up of these patients is required.

In summary, we have identified HBVrt amino acid substitutions in treatment-naïve individuals that could reduce the efficacy of currently used antivirals like lamivudine, adefovir and entecavir. Though no established 
mutations against any of these drugs was seen in these 97 subjects, the presence of compensatory/secondary mutations that usually occur in treatment-experienced individuals alerts that the chance of development of 'hot-spot' primary mutations in these treatment-naïve individuals is higher. There were $17 \mathrm{HBVrt}$ positions that showed genotype-specific amino acid substitutions. Future studies are warranted to identify mutations that would definitely impact on antiviral efficacy, to explore the role of atypical and novel amino acid substitutions, and to determine baseline genotype-specific markers of HBV drug resistance. Baseline characterization of HBVrt sequences will have a promising role in therapeutic management of $\mathrm{HBV}$ as all of the currently available oral drugs target this region.

\section{Acknowledgements}

This work was partly funded by an ICMR grant (No. 5/8/7/ 7/2008-ECD-I).

\section{References}

1 Liaw YF, Gane E, Leung N, Zeuzem S, Wang Y, Lai CL, Heathcote EJ, Manns M, Bzowej N, Niu J, Han SH, Hwang SG, Cakaloglu Y, Tong MJ, Papatheodoridis G, Chen Y, Brown NA, Albanis E, Galil K, Naoumov NV: 2-year globe trial results: telbivudine is superior to lamivudine in patients with chronic hepatitis B. Gastroenterology 2009;136:486-495.

-2 Tenney DJ, Rose RE, Baldick CJ, Pokornowski KA, Eggers BJ, Fang J, Wichroski MJ, Xu D, Yang J, Wilber RB, Colonno RJ: Longterm monitoring shows hepatitis $B$ virus resistance to entecavir in nucleoside-naive patients is rare through 5 years of therapy. Hepatology 2009;49:1503-1514.

-3 Hadziyannis SJ, Tassopoulos NC, Heathcote EJ, Chang TT, Kitis G, Rizzetto M, Marcellin P, Lim SG, Goodman Z, Ma J, Brosgart CL, Borroto-Esoda K, Arterburn S, Chuck SL: Long-term therapy with adefovir dipivoxil for HBeAg-negative chronic hepatitis B for up to 5 years. Gastroenterology 2006;131: 1743-1751.

4 Prevention of Hepatitis B in India - An Overview. New Delhi, World Health Organisation South-East Asia Regional Office, 2002.

5 Locarnini S, Mason WS: Cellular and virological mechanisms of HBV drug resistance. J Hepatol 2006;44:422-431.

6 Stuyver LJ, Locarnini SA, Lok A, Richman DD, Carman WF, Dienstag JL, Schinazi RF: Nomenclature for antiviral-resistant human hepatitis B virus mutations in the polymerase region. Hepatology 2001;33:751-757.

7 Bartholomeusz A, Tehan BG, Chalmers DK: Comparisons of the HBV and HIV polymerase, and antiviral resistance mutations. Antivir Ther 2004;9:149-160.

$\checkmark 8$ Nowak MA, Bonhoeffer S, Hill AM, Boehme $\mathrm{R}$, Thomas HC, McDade H: Viral dynamics in hepatitis B virus infection. Proc Natl Acad Sci USA 1996;93:4398-4402.

-9 Fares MA, Holmes EC: A revised evolutionary history of hepatitis B virus (HBV). J Mol Evol 2002;54:807-814.
10 Borroto-Esoda K, Miller MD, Arterburn S: Pooled analysis of amino acid changes in the HBV polymerase in patients from four major adefovir dipivoxil clinical trials. J Hepatol 2007;47:492-498.

11 Allen MI, Deslauriers M, Andrews CW, Tipples GA, Walters KA, Tyrrell DL, Brown N, Condreay LD: Identification and characterization of mutations in hepatitis B virus resistant to lamivudine. Lamivudine Clinical Investigation Group. Hepatology 1998;27: 1670-1677.

12 Bartholomeusz A, Locarnini SA: Antiviral drug resistance: clinical consequences and molecular aspects. Semin Liver Dis 2006;26: 162-170.

13 Tenney DJ, Levine SM, Rose RE, Walsh AW, Weinheimer SP, Discotto L, Plym M, Pokornowski K, Yu CF, Angus P, Ayres A, Bartholomeusz A, Sievert W, Thompson G, Warner N, Locarnini S, Colonno RJ: Clinical emergence of entecavir-resistant hepatitis B virus requires additional substitutions in virus already resistant to lamivudine. Antimicrob Agents Chemother 2004;48:3498-3507.

14 Colonno RJ, Rose R, Baldick CJ, Levine S, Pokornowski K, Yu CF, Walsh A, Fang J, Hsu M, Mazzucco C, Eggers B, Zhang S, Plym M, Klesczewski K, Tenney DJ: Entecavir resistance is rare in nucleoside naive patients with hepatitis B. Hepatology 2006;44:1656-1665.

15 Wakil SM, Kazim SN, Khan LA, Raisuddin S, Parvez MK, Guptan RC, Thakur V, Hasnain SE, Sarin SK: Prevalence and profile of mutations associated with lamivudine therapy in Indian patients with chronic hepatitis $B$ in the surface and polymerase genes of hepatitis B virus. J Med Virol 2002;68:311318.

16 Norder H, Courouce AM, Coursaget P, Echevarria JM, Lee SD, Mushahwar IK, Robertson BH, Locarnini S, Magnius LO: Genetic diversity of hepatitis B virus strains derived worldwide: genotypes, subgenotypes, and HBsAg subtypes. Intervirology 2004;47: 289-309.
17 Purdy MA, Talekar G, Swenson P, Araujo A, Fields H: A new algorithm for deduction of hepatitis B surface antigen subtype determinants from the amino acid sequence. Intervirology 2007;50:45-51.

18 Liu BM, Li T, Xu J, Li XG, Dong JP, Yan P, Yang JX, Yan L, Gao ZY, Li WP, Sun XW, Wang YH, Jiao XJ, Hou CS, Zhuang H: Characterization of potential antiviral resistance mutations in hepatitis B virus reverse transcriptase sequences in treatment-naive Chinese patients. Antiviral Res 2010;85:512-519.

19 Han Y, Huang LH, Liu CM, Yang S, Li J, Lin ZM, Kong XF, Yu de M, Zhang DH, Jin GD, Lu ZM, Gong QM, Zhang XX: Characterization of hepatitis B virus reverse transcriptase sequences in Chinese treatment naive patients. J Gastroenterol Hepatol 2009;24: 1417-1423.

20 Sayan M, Akhan SC, Meric M: Naturally occurring amino-acid substitutions to nucleos $(\mathrm{t})$ ide analogues in treatment naive Turkish patients with chronic hepatitis B. J Viral Hepat 2010;17:23-27.

21 Pastor R, Habersetzer F, Fafi-Kremer S, Doffoel M, Baumert TF, Gut JP, Stoll-Keller F, Schvoerer E: Hepatitis virus mutations potentially conferring adefovir/tenofovir resistance in treatment-naive patients. World J Gastroenterol 2009;15:753-755.

22 Zhang D, Chen J, Deng L, Mao Q, Zheng J, Wu J, Zeng C, Li Y: Evolutionary selection associated with the multi-function of overlapping genes in the hepatitis B virus. Infect Genet Evol 2010;10:84-88.

23 Tamura K, Dudley J, Nei M, Kumar S: Mega4: Molecular evolutionary genetics analysis (MEGA) software version 4.0. Mol Biol Evol 2007;24:1596-1599.

24 Lazarevic I, Cupic M, Delic D, Svirtlih NS, Simonovic J, Jovanovic T: Distribution of HBV genotypes, subgenotypes and HBsAg subtypes among chronically infected patients in Serbia. Arch Virol 2007;152:20172025. 
-25 Lusida MI, Nugrahaputra VE, Soetjipto, Handajani R, Nagano-Fujii M, Sasayama M, Utsumi T, Hotta H: Novel subgenotypes of hepatitis $\mathrm{B}$ virus genotypes $\mathrm{C}$ and $\mathrm{D}$ in $\mathrm{Pa}$ pua, Indonesia. J Clin Microbiol 2008;46: $2160-2166$

-26 Ciancio A, Smedile A, Rizzetto M, Lagget M, Gerin J, Korba B: Identification of HBV DNA sequences that are predictive of response to lamivudine therapy. Hepatology 2004;39: 64-73.

27 Bottecchia M, Madejon A, Sheldon J, GarciaSamaniego J, Barreiro P, Soriano V: Hepatitis $B$ virus genotype A2 harbours an L217R polymorphism which may account for a lower response to adefovir. J Antimicrob Chemother 2008;62:626-627.

-28 Solmone M, Vincenti D, Prosperi MC, Bruselles A, Ippolito G, Capobianchi MR: Use of massively parallel ultradeep pyrosequencing to characterize the genetic diversity of hepatitis $B$ virus in drug-resistant and drug-naive patients and to detect minor variants in reverse transcriptase and hepatitis B S antigen. J Virol 2009;83:1718-1726.

-29 Vivekanandan P, Abraham P, Sridharan G, Chandy G, Daniel D, Raghuraman S, Daniel HD, Subramaniam T: Distribution of hepatitis $\mathrm{B}$ virus genotypes in blood donors and chronically infected patients in a tertiary care hospital in southern India. Clin Infect Dis 2004;38:e81-e86.

-30 Vivekanandan P, Daniel HD, Raghuraman S, Daniel D, Shaji RV, Sridharan G, Chandy G, Abraham P: Novel digestion patterns with hepatitis B virus strains from the Indian subcontinent detected using restriction fragment length polymorphism. Indian J Med Microbiol 2008;26:96-97.
Banerjee A, Datta S, Chandra PK, Roychowdhury S, Panda CK, Chakravarty R: Distribution of hepatitis $B$ virus genotypes: phylogenetic analysis and virological characteristics of genotype $\mathrm{C}$ circulating among HBV carriers in Kolkata, eastern India. World J Gastroenterol 2006;12:5964-5971.

32 Banerjee A, Kurbanov F, Datta S, Chandra PK, Tanaka Y, Mizokami M, Chakravarty R: Phylogenetic relatedness and genetic diversity of hepatitis B virus isolates in eastern India. J Med Virol 2006;78:1164-1174.

33 Chandra PK, Biswas A, Datta S, Banerjee A, Panigrahi R, Chakrabarti S, De BK, Chakravarty $\mathrm{R}$ : Subgenotypes of hepatitis B virus genotype D (D1, D2, D3 and D5) in India: differential pattern of mutations, liver injury and occult HBV infection. J Viral Hepat 2009;16:749-756.

34 Banerjee A, Chandra PK, Datta S, Biswas A, Bhattacharya P, Chakraborty S, Chakrabarti S, Bhattacharya SK, Chakravarty R: Frequency and significance of hepatitis $B$ virus surface gene variant circulating among 'antiHBc only' individuals in eastern India. J Clin Virol 2007;40:312-317.

35 Kumar GT, Kazim SN, Kumar M, Hissar S, Chauhan R, Basir SF, Sarin SK: Hepatitis B virus genotypes and hepatitis $B$ surface antigen mutations in family contacts of hepatitis $B$ virus infected patients with occult hepatitis B virus infection. J Gastroenterol Hepatol 2009;24:588-598.

36 Villet S, Pichoud C, Billioud G, Barraud L, Durantel S, Trepo C, Zoulim F: Impact of hepatitis B virus rtA181V/T mutants on hepatitis B treatment failure. J Hepatol 2008;48: 747-755.

- 37 Schildgen O, Olotu C, Funk A, Zollner B, Helm M, Rockstroh JK, Sirma H: Selection and counterselection of the rtI233V adefovir resistance mutation during antiviral therapy. J Clin Microbiol 2010;48:631-634.
38 Curtis M, Zhu Y, Borroto-Esoda K: Hepatitis $B$ virus containing the I233V mutation in the polymerase reverse-transcriptase domain remains sensitive to inhibition by adefovir. J Infect Dis 2007;196:1483-1486.

39 Tan J, Degertekin B, Wong SN, Husain M, Oberhelman K, Lok AS: Tenofovir monotherapy is effective in hepatitis B patients with antiviral treatment failure to adefovir in the absence of adefovir-resistant mutations. J Hepatol 2008;48:391-398.

40 Xiong X, Yang H, Westland CE, Zou R, Gibbs CS: In vitro evaluation of hepatitis $B$ virus polymerase mutations associated with famciclovir resistance. Hepatology 2000;31:219224

41 Torresi J, Earnest-Silveira L, Civitico G, Walters TE, Lewin SR, Fyfe J, Locarnini SA, Manns M, Trautwein C, Bock TC: Restoration of replication phenotype of lamivudineresistant hepatitis B virus mutants by compensatory changes in the 'Fingers' subdomain of the viral polymerase selected as a consequence of mutations in the overlapping S gene. Virology 2002;299:88-99.

42 Wallace WA, Carman WF: Surface variation of HBV: scientific and medical relevance. Viral hepatitis review 1997;3:5-16.

43 Kazim SN, Chauhan R, Das BC, Sarin SK: Association of core promoter mutations with viral breakthrough in chronic hepatitis B patients on long-term lamivudine therapy. J Gastroenterol Hepatol 2006;21:1525-1532.

44 Fukai K, Zhang KY, Imazeki F, Kurihara T, Mikata R, Yokosuka O: Association between lamivudine sensitivity and the number of substitutions in the reverse transcriptase region of the hepatitis $\mathrm{B}$ virus polymerase. J Viral Hepat 2007;14:661-666.

45 Ghany M, Liang TJ: Drug targets and molecular mechanisms of drug resistance in chronic hepatitis B. Gastroenterology 2007; 132:1574-1585. 